\title{
Strengthening Faculty Development Programs Through Evaluation
}

\section{Ann Ferren and Kay Mussell}

The American University

Research on faculty development suggests that a college can choose from an extensive range of activities in designing a faculty development program, but that an institution is limited to a development process that matches faculty expectations-or it risks failure. William Nelsen (1979) reported in his study of twenty faculty development programs that "how a college carried out its faculty renewal program was equally important, perhaps more important, than what it proposed to do." Although Nelsen found considerable information on program activities, few institutions could describe with much clarity or consciousness their thinking about the process of faculty development. Consequently, when the College of Arts and Sciences at American University received a grant to support faculty development, our initial planning focused primarily on how to carry out a program that made sense in our own institutional context. At the same time, however, we sought an evaluation process to complement our particular program and to enable us to assess our activities and success after the first few years. It is the procedure and the results of that evaluation that we describe here.

Drawing on guidance from others and our own preliminary needs assessment, we designed a "faculty-responsive" program characterized by faculty involvement in planning, voluntary participation, open access to activities, flexibility in program 
services, regular communication about the program, and systematic evaluation of individual projects. The College established an Office of Faculty Support, with a modest collection of reference materials, including books on teaching strategies, curriculum development, grants, and evaluation procedures. The primary resource of the office, however, was the Director, a person with time, ideas, money, and a concern for individual faculty members. All ideas, small grants, and workshops were approved by the Faculty Steering Committee, which represented the curriculum fields of the college. The office publicized activities widely within the college, and a quarterly newsletter reported regularly on funded projects. Each semester, the formal schedule was laid out in advance, and faculty members could sign up for several projects or activities. At the same time, the Director and Steering Committee targeted particular faculty members to be specially invited to workshops, either for their expertise or their expressed needs. Additional projects and services were planned as issues arose. Faculty members could participate often or not at all, and individuals frequently had several projects going at once.

From the beginning, the Faculty Development Program had multiple aspects. The Director met with departments, with chairpersons, and with individuals to publicize project guidelines and to learn about perceived needs. The Steering Committee sponsored workshops on such common issues as effective teaching, writing instruction, computer literacy, and sabbatical planning. Individuals could apply for small grants to fund teaching materials and other professional development. Departments were encouraged to use faculty development resources in assessing their own continuing and future needs. Individuals could request classroom visits and confidential assessments of their teaching strategies by the Director. Throughout, the Director and the Steering Committee concentrated on supporting faculty members' expressed needs, giving special consideration to those requests that improved teaching effectiveness. In addition, the Director and Steering Committee remained flexible in response to applications, always remembering that the program should be open to changes in direction. After establishing a facultyresponsive program, we turned to the design of a "programresponsive" evaluation process. 


\section{THEORETICAL FRAMEWORK FOR PROGRAM EVALUATION}

A review of the literature on faculty development provides valuable guidance for program design; unfortunately, there is little guidance available for designing effective evaluation (Stordahl, 1981). Evaluations of faculty development programs often have been accused of being self-serving and unrealistic. The need for evaluation is clearly established, but successful models for evaluation are woefully underdescribed.

The usual approaches to education program evaluation, including experimental and quasi-experimental designs, are inappropriate to a program aimed at serving everyone. The control group, in our case, would have been self-selected nonparticipants; and the experimental group would have differed considerably, for it consisted of enthusiastic volunteers with clear needs. In addition, faculty development program evaluation is problematic because the multiplier effect is at work. As a program continues over time, additional participants become involved through the recommendations and enthusiasm of colleagues. Projects that initiate faculty into thinking about teaching strategies, for example, become more sophisticated as participation grows. Barriers to participation shift. It is difficult to pinpoint an appropriate time frame for measuring program effects.

In one of the few analyses of faculty development program evaluation, Jon F. Wergin (1977) confirms that “. . Evaluation should reflect the nature of the program." If careful attention should be paid to how a program is carried out, we concluded that how a program is evaluated would also be important. Consequently, we designed a non-intrusive formative evaluation process to be congruent with-indeed, to reinforce-the nature of the program. On an annual basis, the program had used traditional data-gathering procedures: statistics on participation; narrative assessments of faculty projects; and ratings of workshops for participant satisfaction, appropriateness, and applicability. While we knew how each activity or project had fared, we also needed to evaluate the program's cumulative progress toward meeting its overall goals and to provide guidance for mid-course corrections.

Consequently, we were persuaded by Wergin's strong advocacy of the case study method, which can make use of all 
historical documentation in addition to data "from both the consumer's and the practitioner's view." Such an in-depth analysis relies on data-gathering from a variety of sources and a careful analysis based on "convergence of findings" and "probable explanations of disagreements" (Wergin 1977).

\section{METHODS AND DATA SOURCES}

Four faculty members were selected to serve as an evaluation team. One had been a member of the Faculty Development Steering Committee during its crucial first year and was widely recognized on campus for academic leadership. One was from another college within the University; he had no contact with this program but he had evaluated faculty development programs for other universities. A third was an untenured faculty member who had not participated in the program during its first two years. The fourth, the team's chair, had been familiar with the program in its early stages but had been away from the University on a full-year sabbatical. She had been appointed to the Faculty Development Steering Committee and was to use the evaluation work as a "quick orientation" to the program.

The evaluation team had access to the program's extensive written documentation, which included an effective mechanism for keeping track of grant projects and for reporting to the faculty on grant activities. The files in the office were thorough and impressive; the newsletter spread the word through short articles on areas of broad faculty concern, listings of all grants approved, reports on workshops, and announcements of upcoming activities. Quarterly director's reports to the Dean of the College outlined progress toward meeting program goals, reported on perceived needs within the college, and proposed strategies for meeting developing priorities. A content analysis of these data was the essential starting point for the program evaluation.

The primary question guiding the evaluation team was not "What has been accomplished?" but "How have faculty members been affected?" If the Faculty Development Program had been judged only on its activity level and its success in reaching large numbers of faculty members in each department, the evaluation team's work would have been completed after one 
meeting. The program had been active, its director had high visibility, and over 80 percent of the faculty had participated. By any traditional measure, the program was a success.

But the team agreed from the beginning that faculty perceptions about the program and real changes in behavior would be more significant and valuable than impressive records and statistics. Consequently, participation in an activity or gross numbers of involved faculty members would not be enough to demonstrate success. Instead, the evaluation should measure impact through the attitudes, behaviors, and commitments of the participants over time. The team gave special attention to the effects of the program's process: open access to all activities, ease of application for grants, an effective mix of projects for individuals and groups, and overall responsiveness to specific needs articulated by faculty.

The evaluation team sent a questionnaire to each of the 230 faculty members in the College. The response rate was almost 25 percent in two weeks, and completed forms continued to return for a month after the evaluation ended. Some faculty members did not respond because they had not been involved, by their own choice. Others were too busy to fill out the form. Those are the facts of life in the College, and it was essential to the spirit of the evaluation to use only the data that were freely forthcoming rather than press for a response from additional faculty.

The heart of the evaluation process was interviews. We selected 30 faculty members to be interviewed in depth - a minimum of one hour of discussion focused on both the activities of the Faculty Development Program and the individual's own priorities as a scholar and teacher. We aimed for a broad range of potential responses by selecting faculty from various categories: tenured and nontenured, active or inactive in faculty development projects, from different departments, and with different priorities-from those whose primary concerns were in teaching to those with reputations as effective scholars. We paid special attention to how the program might address individual priorities in its next two years.

We had, then, the records that provided the rationale for the program, the description of activities, and evidence of how the program had evolved. We had a sample of faculty responses to help us focus on strengths and weaknesses. And finally, 
we had rich information from the interviews against which the other data could be tested for evidence of intensity of feelings of support, relative merits of each type of activity, commitment to maintaining or de-emphasizing parts of the program, changes in behavior, and readiness for new directions. As the evaluation team used these three data sources to identify the real effects of the program on the College as a whole, the results reaffirmed the effectiveness of the case-study method of evaluation.

\section{FINDINGS}

The findings from the evaluation provided evidence of program success as well as directions for the future. The findings were both unique to the program being evaluated and indicative of the impact that faculty development can have on a campus.

Perhaps our most important finding was that collegiality and morale in the College had been substantially improved-not because of any specific activities of the program (although each respondent cited preferences among the range of options) but through the simple existence of the Faculty Development Program in the first place. This was not an insignificant finding. Over and over, in every context, faculty members cited the value of increased collegial contacts.

Workshop participants mentioned the value of discussing common problems with people they had never met before. Those who had attended the writing workshops, for example, were particularly articulate on this point. Many reported that the most valuable result of the workshop was simply talking to others who shared their concerns about the quality of student writing and who wanted to hold students to higher standards. Many reported that before the workshop they had despaired of teaching writing in addition to the disciplinary material they had to cover in each course.

Another activity that was universally praised was the annual faculty colloquium, a three-day seminar of readings, presentations, and discussions among interested faculty members from all departments. Many had never heard colleagues talk about their areas of special expertise; and few had engaged in intellectual discussion of common issues with persons outside their own departments. We discovered that faculty members were not only willing to commit time to preparing for 
the colloquium, but that participants felt enriched by the opportunity to discuss "real issues and ideas" with colleagues instead of meeting only in committees and department meetings that focus, inevitably, on "housekeeping." The value of the colloquium cannot be overstated. Faculty members expressed admiration for the quality of their colleagues' work. They requested more opportunities to interact on professional levels, and they were eager to suggest future topics.

Respondents also reported increased efficiency and effectiveness in other college activities because information about colleagues' interests and activities was no longer a secret. We had discovered, then, that communication in the College, which had long been a problem, had been improved through the Faculty Development Program. Others reported improved morale because they knew there was one special place on campus where someone cared about their needs. The program was a boost to morale even for those who did not participate directly, because it indicated administrative commitment to faculty concerns.

Although the Faculty Development Program had not miraculously solved everyone's problems, few respondents cited the program or its activites as a source of concern. Many needs were beyond the scope of the Faculty Development Program. A few respondents criticized specific grants they perceived as wasteful. In several cases, the evaluation team members were able to correct erroneous perceptions and to defuse negative attitudes toward the College. We learned that dissemination of all program information had been important to avoid resentment.

These findings supported others indicating that the interactive process of the Faculty Development program was as important as the actual funds disbursed. Most of the grants were for relatively small amounts of money, but it was clear that even very small grants had made a significant difference in the way a faculty member's work proceeded. The purchase of a set of slides for a course or the payment of a fee for an inservice training session could energize the recipient for months. In addition, faculty members appreciated the faculty leadership of the program. They commented specifically on the supportive role of the Director and the care, frugality, and apparent thoughtfulness of their colleagues on the Steering Committee 
when considering grants and projects. Clearly, the careful attention to process had an impact on support for the program.

The evaluation team's recommendations to the Steering Committee spoke to several issues for the future. Research support emerged as the most important unmet need in the College. The team suggested that the committee continue its workshop offerings but that it move in new directions, specifically to address student perceptions of teaching effectiveness, encourage small group interaction, and support computer usage. In addition, the team recommended that one additional faculty member be appointed to the Steering Committee. The team also noted that the program's commitment to support of courses for the University's new General Education Program had been ineffective and should be a high priority issue in the future. Overall, the evaluation report recommended that the Faculty Development Program continue its concern for individual faculty needs, maintain a "responsive" process, continue its past focus, and expand in some new directions.

The Steering Committee responded positively. Within a year, a project for research support had begun to address research and equipment needs for faculty at all levels, from the most productive to those who were just beginning their careers. The computer workshop was expanded to include large and small working groups and demonstrations on microcomputers. Additional writing workshops began on a successively higher level of discussion than previous sessions, indicating that dissemination on this issue had moved beyond the original workshops participants. A successful workshop on student perceptions of teaching brought together students and faculty to share common concerns. The Steering Committee sponsored a workshop on course design for the new General Education Program.

\section{IMPLICATIONS}

A "faculty responsive" program benefits from "responsive evaluation" for several reasons. The opportunity to respond to a questionnaire reminded faculty members of the program's commitments to general support of their individual needs. It gave us the opportunity to reiterate guidelines and priorities, which in turn encouraged faculty members to apply for funds. 
It identified activities that should be continued or expanded and targeted others that had reached the limits of their effectiveness. It prompted a reorientation of priorities in the areas of research and attention to student perceptions. In addition, by allowing us to check our formal data sources against faculty perceptions, it provided the Steering Committee with a more complex and sophisticated sense of its mission.

Initially, we decided to evaluate our program because it was the "right thing to do." In retrospect, it was important in its own right. The evaluation process itself was a catalyst for the program's future direction. And if we can make any predictions about the future of faculty development in higher education, formative evaluation on a regular basis will be essential to assure that programs evolve and remain effective.

First, formative evaluation accomplishes exactly what its design implies: it allows a program to develop, maintain, and correct itself. Because faculty development is a fluid, dynamic process, information-gathering is essential in facilitating and shaping its evolution. Formative evaluation can prevent the complacency of thinking of a program as "being in place," and it assures that the program continues to evolve with care and thought.

Second, formative evaluation can ward off and, in our case, overcome major setbacks. A program will not die an unexplained death, subject itself to the stigma of irrelevance, or incur accusations of administrative callousness if it pays careful attention to participant perceptions. The General Education Program we were to help support bogged down in political and administrative squabbles. The evaluation team members served as advocates for "forgiveness" and kept the Faculty Development Program from being tainted by a curricular failure that was beyond its control.

Third, while the information was significant to the Steering Committee in planning for the future, the opportunity to be heard was an improtant shot in the arm for participants as well. It underscored the program's commitment to respond to faculty needs; and the reported results of their colleagues' evaluation added to the positive attitudes that had been developed by the "faculty-responsive" program. In some cases, the evaluation also made it possible to re-shape expectations.

Fourth, formative evaluation serves as an ongoing needs 
assessment. Since the success of a program depends on meeting faculty needs-needs that are never static-there must be a legitimate and focused way to assess the changing priorities of both the institution and the faculty. It takes time for faculty members to trust a program and ask for support for their genuine needs. In our case, few faculty members were willing to state at the outset that they needed help with teaching. As teaching workshops promoted confidence in the program, however, faculty members identified their own concerns and urged the program to provide support.

\section{CONCLUSIONS}

Since faculty development programs are designed to fit unique institutional contexts, program evaluation need not be concerned with replicability. The case study method is both appropriate and informative, for it is sensitive and subtle enough to match a program's process without interfering with its ongoing direction. A program can change goals or procedures with no threat to the validity of the findings. Maturation, which is a threat to internal validity under experimental conditions, is essential to the success of faculty development programs and can be reinforced by "responsive evaluation."

The twin processes of development and evaluation can proceed in a complementary and interactive way. Our program was designed to be responsive; but it is clear that faculty development as we have known it is going to change. It has been a luxury to focus on individual interests such as improved teaching, innovative curricula, new ways to handle lectures or labs, or travel to conferences. In the coming years, however, faculty development will be less an opportunity than a necessity.

If faculty development is to have meaning and support, it must match the needs of both the institution and its faculty members. The very real pressure that steady-state planning places on faculty utilization will mean that faculty support must have two emphases: those activities that are chosen by faculty members to meet their individual needs as scholars and teachers and those activities offered by the university to encourage faculty members to match the needs of the institution. At best, institutional priorities and faculty development should reinforce each other. A faculty development 
program that is "responsive," through its process and ongoing evaluation, can provide an essential link between the development priorities of institutions and individuals.

\section{REFERENCES}

Bergquist, W. H. and Phillips, S. R. (1975). A handbook for faculty development. Washington, D. C.: The Council for the Advancement of Small Colleges.

Gaff, J. G. (1975). Toward faculty renewal. San Francisco: Jossey-Bass.

Nelsen, W. C. (1979). Faculty development: Key issues for effectiveness. Forum, 2(1), 1-4.

Nelsen, W. C. and Siegel, M. E. (1980). Effective approaches to faculty development. Washington, D. C.: Association of American Colleges.

Pellino, G., et al. (March, 1980). Faculty development programs, the improvement of instruction, and faculty goals: An evaluation. Paper presented at the AAHE national conference on higher education, Washington, D. C.

Preus, P. K. and Williams, D. F. (1979). Personalized faculty development. Bear Creek, Ala.: CESCO Press.

Stordahl, B. (March, 1981). Faculty development: A survey of literature of the 70's. AAHE Bulletin, 7-10.

Wergin, J. F. (1977). Evaluating faculty development programs. In J. A. Centra (Ed.), Renewing and evaluating teaching. San Francisco: Jossey-Bass. 